\title{
SOVEREIGN RISK ANALYSIS OF DEVELOPING COUNTRIES: FINDINGS FROM CREDIT DEFAULT SWAP PREMIUM BEHAVIOUR
}

\author{
Moch. Doddy Ariefianto dan Soenartomo Soepomo ${ }^{1}$
}

\begin{abstract}
This study conducts econometric analysis CDS Premium relations towards variables usually used as a sovereign rating explanatory. Estimation with data panel econometric found that global risk appetite is the most important influencing variable followed by foreign exchange reserve and yield spread. This item is consistent with the existing empiric literature and shows a high correlation between developing countries economy and world economic cycle.
\end{abstract}

JEL Classification : F34, F32, G13, G15, C23

Keywords: Sovereign Risk, Credit Default Swap, Panel Data

1 The authors are lecturer in Economic and Business Faculty, University of Ma Chung, Malang; doddy.ariefianto@machung.ac.id and soenartomo.soepomo@machung.ac.id. 


\section{INTRODUCTION}

Foreign debt has already become important source of fund in developing countries. This external financing is needed in order to fill the saving-investment gap that is usually negative. Foreign debt can be in any forms such as government debt, government bond, corporate bond, bilateral-multilateral loan, etc.

The price of the loan depends on the scheme, economic condition (fiscal and monetary), and reputation. In some decades recently, there is a kind of institution trend that does specialization in debt valuation. This institution, which is always called as rating agency institution, measures the ability of certain entity, quantitatively and qualitatively, to pay (credit risk) and give this entity a ranking. Special for sovereign entity, the rating has been established since 1975 by Standard and Poor's (Beers and Cavanaugh, 2006).

Credit risk measurement is not actually new. A credit risk model in default probability form has been formulated by Altman with his famous Z-statistics in 1968. The development of credit risk modeling is already advanced including its sophisticated statistic technique and calibration of variables used. Cantor (2004) gave a review about the credit risk modeling.

The sovereign risk is important and attracting a huge attention of investors. Unlike private credit risk, investor cannot seize the collateral or government income when event default occurs. That is why the credit valuation for government loans becomes more important.

As credit corporate risk, sovereign risk can also be influenced by domestic and international condition (Beers and Cavanaugh, 2006), including economic or political condition. Fiscal pressure, for instance, caused by large outstanding debt and government deficit, can force the government to delay the installment and interest payment as well as the regime transformation caused by political turbulence. The ruling government today can reject the debt from previous government.

Interaction pattern of modern economic nowadays has a very high interrelation one another. Practically, there are no countries that can isolate their economy from external shock. Subprime mortgage crisis in the US in 2007 and the world economic contraction during 2008-2009 are the real evidences in terms of high interrelation among countries. Thus, a country can experience an economic crisis as the impact of external turbulence, and make the existing government to restructure their loan payment.

Further innovation in credit risk management in the early $21^{\text {st }}$ century is the emergence of Credit Default Swap (CDS). This derivative instrument has a function like bond insurance. 
CDS holder (called as protection buyer) can exchange his bond with the sum of nominal face value, to CDS seller (protection seller) in the case of default (Taylor, 2007). To get this protection, CDS buyer must pay a certain premium (stated in percentage of debt).

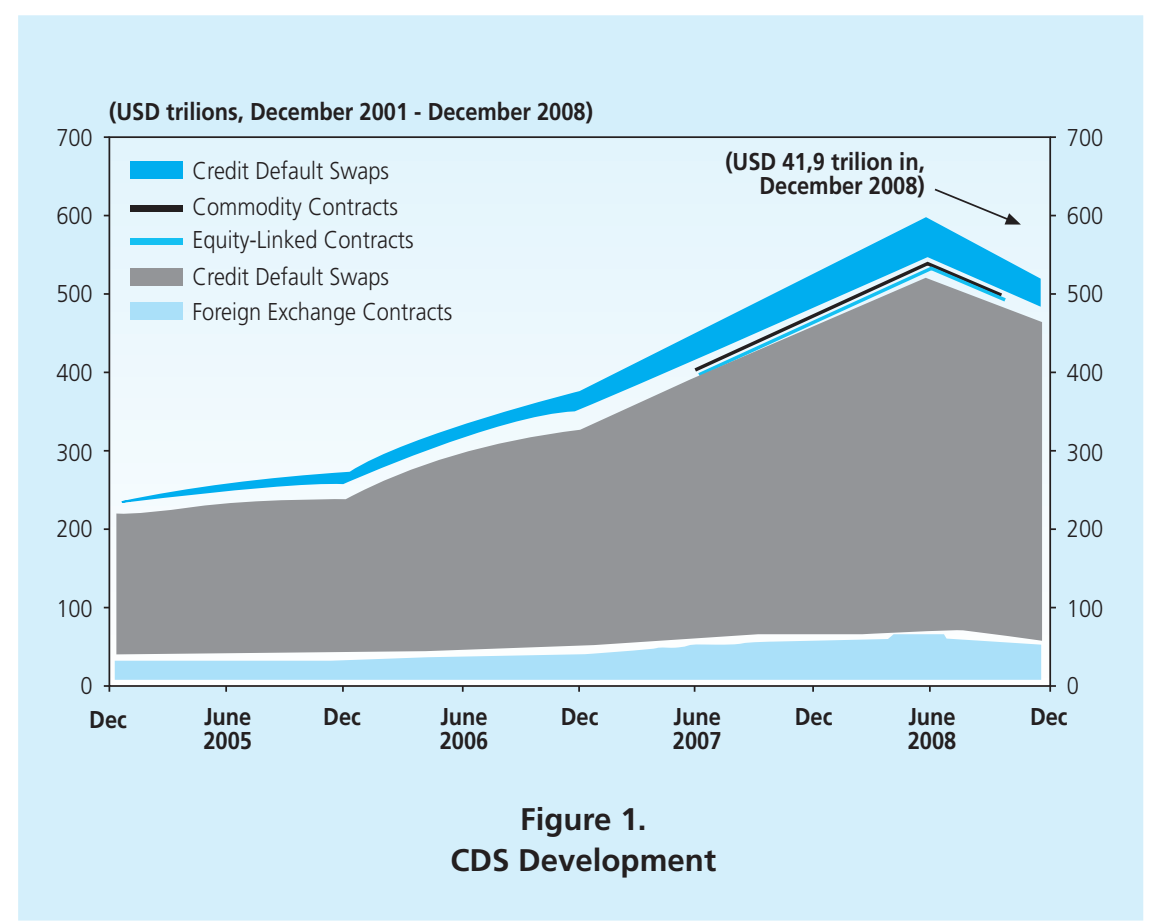

Data from Bank for International Settlement (BIS) shows, since firstly introduced in 2005, CDS contract value has achieved USD 41.9 Trillion as for December 2008 (Figure 1). Even with rapid development, CDS position is considered too small among other derivative instruments. Interest derivative, for instance, is valued at USD 403 at the same period. Even its reputation is deceived by negative impact from the subprime mortgage, Hull (2011) predicted that this instrument has a bright prospect in the future.

Sovereign CDS for developing countries is started within the same period. There is a high correlation between CDS movement with the change of a country's rating (Ismailescu and Kazemi, 2010). Thus, the based rating change can explain the CDS movement. Furthermore, CDS is potential to be leading indicator for financial market.

This research is conducted to reveal the relation between CDS and sovereign rating as its explanatory variables. The outcome of the study is expected to benefit not only academician, 
but also for policy maker. This paper consists of five sections. Next section presents the theory and empirical literature about CDS. The third section explains the methodology of research including our empirical scheme. The forth section discusses result and analysis, while conclusion and policy implication will close the presentation.

\section{THEORY}

\subsection{CDS Valuation Overview}

Duffie (1999) suggested to considering CDS as swap default able floating rate notes towards default free floating rate note. As a swap, the owner of CDS has a right to exchange his default-able instruments with the cash flow from default free instrument that belongs to swap seller. This swap is triggered when the credit event occur. The credit event can be in any forms such as outright default from underlying securities issuer, restructuring, rescheduling, or even just the postponement of interest/installment payment (Hull, 2011).

Skinner and Townend (2002), in the other hand, used a put option approach in valuing CDS. As a put option, CDS buyer has a right to sell securities that belong to him at par value when credit event occurred. Furthermore, they also explained that CDS premium meet the put and call parity:

$$
X e^{-r t}-B<p<X+D-B
$$

Where $X$ is noticed as strike price from the option (par value), $B$ is noticed as a security that contain credit risk, $p$ is CDS premium, $D$ is coupon value, and $r$ is interest rate of risk free portfolio. They showed that this inequality will be fulfilled, so that the CDS premium is analogue to the premium of an option.

Whetten et al (2004), on the other hand, use the insurance approach. A CDS buyer gets insurance upon the minimum underlying securities price. If the event credit occurred, then CDS buyer can exchange his securities with cash at par value. In another scheme, CDS buyer can sell securities himself and CDS seller would compensate its deviation to the par value. In other words, CDS seller just pays (1-a), where $a$ is security market value after credit event occur (recovery rate), see Figure 2 . 


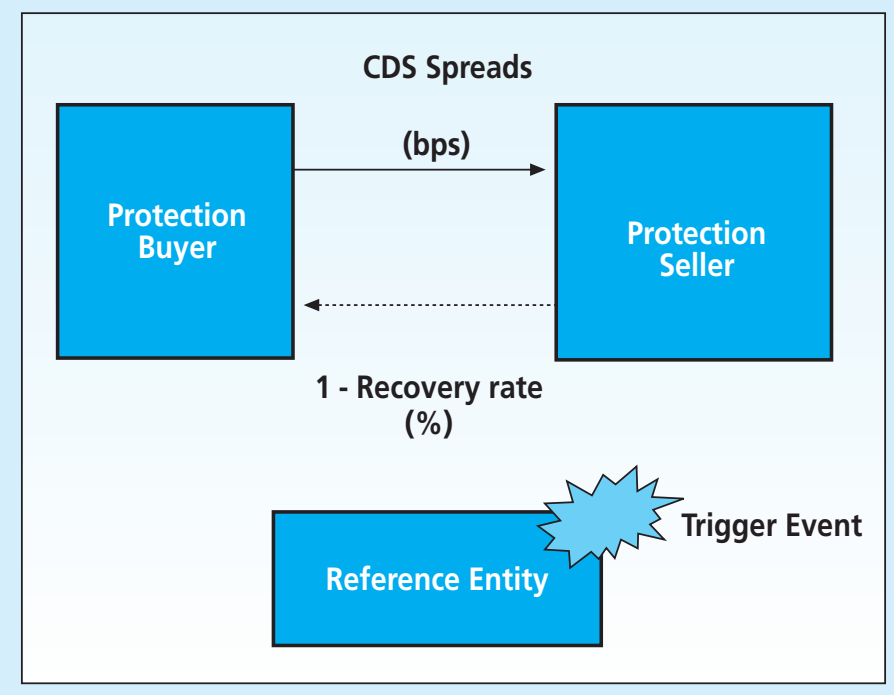

Source : Whetten et al (2004)

Figure 2. CDS Scheme

By using the approach from Whetten et al (2004), the premium from CDS can be measured as follow:

1. There are 2 types of cash flow from CDS transaction, which are fixed premium payment from CDS buyer and contingency cash flow that is paid by CDS seller only if credit event occurred.

2. CDS value (for buyer) is the present value of all contingency cash flow minus fixed cash flow.

3. Fixed cash flow depends on nominal premium on each period and survival ability ${ }^{2}$. If premium is noticed as $S, d_{i}$ is payment period (as an annual fraction), $q\left(t_{i}\right)$ is survival rate and $D\left(\mathrm{t}_{\mathrm{i}}\right)$ is adjusted discount factor, then the present value can be formulated as follow ${ }^{3}$ :

$$
\sum_{i=1}^{T} D\left(t_{i}\right) \cdot q\left(t_{i}\right) S d_{i}+\sum_{i=1}^{T} D\left(t_{i}\right)\left\{q\left(t_{i-1}\right)-q\left(t_{i}\right)\right\} S \frac{d_{i}}{2}
$$

2 If credit event happens, then CDS buyer does not need to pay. Thus there is probability that in a period, CDS buyer does not need to pay premium because the credit event happens. One minus this probability is called survivalability.

3 The second part of formula 2 is premium payment accrual value if default occurs between payment period $\mathrm{t}_{\mathrm{i}-1}$ and $\mathrm{t}_{\mathrm{i}}$. 
4. Whereas the number of contingency cash flow can be calculated as a difference of recovery rate $(\mathrm{R})$ from the par value, or

$$
(1-R) \sum_{i=1}^{T} D\left(t_{i}\right)\left\{q\left(t_{i-1}\right)-q\left(t_{i}\right)\right\}
$$

5. In equilibrium condition, premium value will equalize the fixed and contingency cash flow payment, or explicitly stated:

$$
\sum_{i=1}^{T} D\left(t_{i}\right) q\left(t_{i}\right) S d_{i}+\sum_{i=1}^{T} D\left(t_{i}\right)\left\{q\left(t_{i-1}\right)-q\left(t_{i}\right)\right\} S \frac{d_{i}}{2}=(1-R) \sum_{i=1}^{T} D\left(t_{i}\right)\left\{q\left(t_{i-1}\right)-q\left(t_{i}\right)\right\}
$$

6. With a little math, we can obtain the CDS premium valuation as follow:

$$
S=\frac{(1-R) \sum_{i=1}^{T} D\left(t_{i}\right) \cdot\left\{q\left(t_{i-1}\right)-q\left(t_{i}\right)\right\}}{\sum_{i=1}^{T} D\left(t_{i}\right) \cdot q\left(t_{i}\right) d_{i}+\sum_{i=1}^{T} D\left(t_{i}\right) \cdot\left\{q\left(t_{i-1}\right)-q\left(t_{i}\right)\right\} \frac{d_{i}}{2}}
$$

\subsection{Sovereign Rating Approach Towards CDS Premium ${ }^{4}$}

Sovereign rating is credit risk evaluation for government entity, and not specifically for certain issuer. The rating reflects credit risk evaluation for all entities in a country. The other credit risk entity would always be smaller or equal with sovereign rating. Thus, the sovereign rating becomes very important since the domestic credit price will be affected if the sovereign rating degrades.

Sovereign default occurrence declined during 1970-1980s but it increased even still below the average in 1900-1950s (see Figure 3). The decline was because the traditional factors that worsen the fiscal condition (such as the wars, revolution, and the policy that are not prudent) had decreased drastically. In modern era, the weakness of debt management, the low economic productivity, and the contingent liabilities (from the collapse of banking system) are the main reason of sovereign default.

4 Most of material in this part are summarized from Beers and Cavanaugh (2006) 


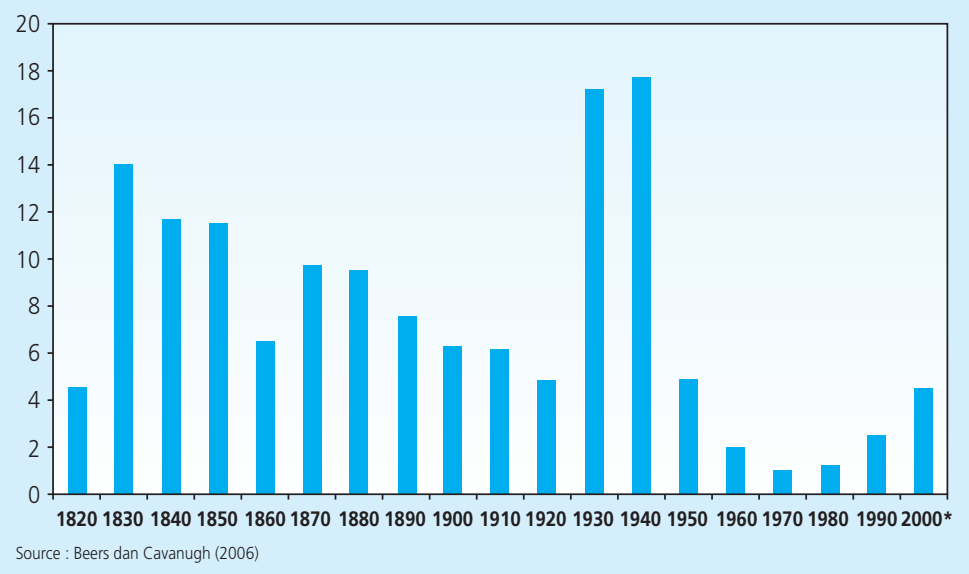

Figure 3.

Sovereign Default 1800-2000.

The calculation of credit rating is conducted through a proprietary model that covers quantitative and qualitative aspects (Cantor, 2004). Even the calculation technique and variables can be different from one institution to other institutions, we can find basic similarities among them.

First, there are two components of credit evaluation which are rating and outlook. The rating gives a rate or agency value towards the standing of credit risk for certain institution. The rating gradation is varying, but they generally consist from very high to default. Whereas the outlook (or watchlist) predict the prospect or direction of the credit risk for the next certain period (usually 6 months to 2 years). The marks in the outlook can be:
a. Stable
: If the rating is not predicted to change
b. Positive
: If the rating is predicted to increase
c. Negative
: If the rating is predicted to decline ${ }^{5}$

Second, macroeconomic and political variables are used to measure the rating and the credit risk prospect. For instance, Standard and Poor use the following variable categories :
a. Political risk
b. Aggregate economic structure

5 Bannier and Hirsch (2010) did an interesting empiric studies about the use of outlook rating and how it influences investor perception 

c. Economic growth prospect
d. Fiscal condition and fiscal policy
e. Contingency position (domestic)
f. Monetary policy and condition
g. External policy and condition.

The combination use of all these variables is based on judgment and there is no fixed rule. Dynamic economic and political condition causes the influencing value of a variable changes time by time.

Nevertheless, a hierarchy consistency of analysis is still used. For instance, the larger fiscal deficit of a country, the more possible its credit rating gets lower (see Figure 4.a.). There is no dominant factor, and a variable is considered relatively. Figure 4.b shows that the median of government debt ratio towards GDP at AA rating is apparently higher than the A rating.

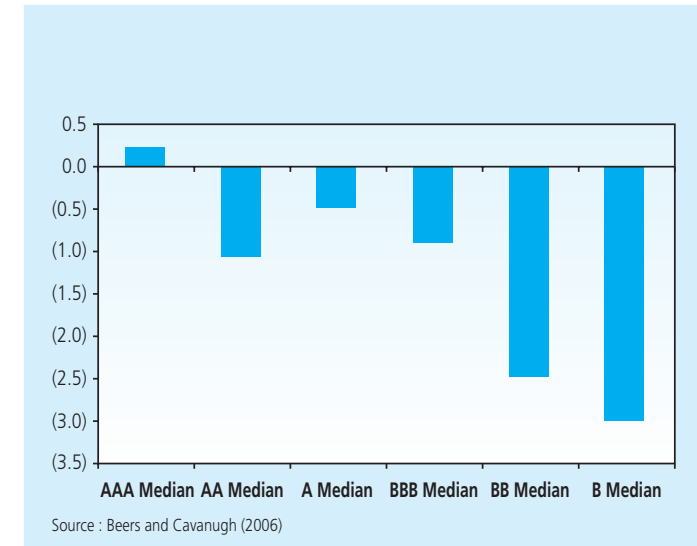

(a) Fiscal Deficit Ratio Towards GDP
(\%)

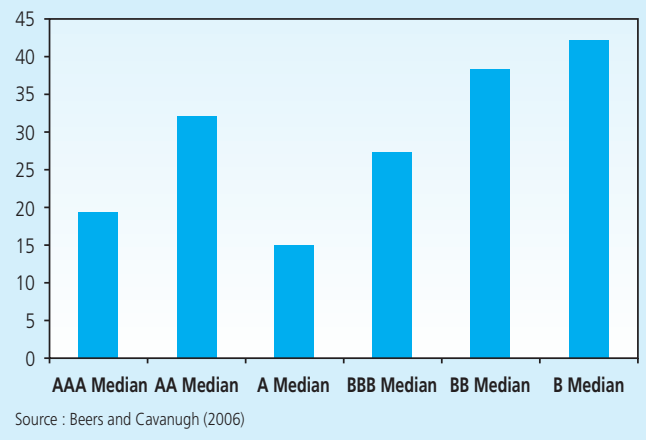

(b) Government Debt Ratio Towards GDP

Figure 4.

Evaluation in Credit Rating S\&P

There is a negative correlation between CDS Premium and sovereign rating. Countries with lower sovereign rating averagely pay higher CDS premium (see Figure 5). Thus even though the CDS is a tradable derivative instrument, the purchasing-selling decision by market traders, in general is in line with the credit rating. 


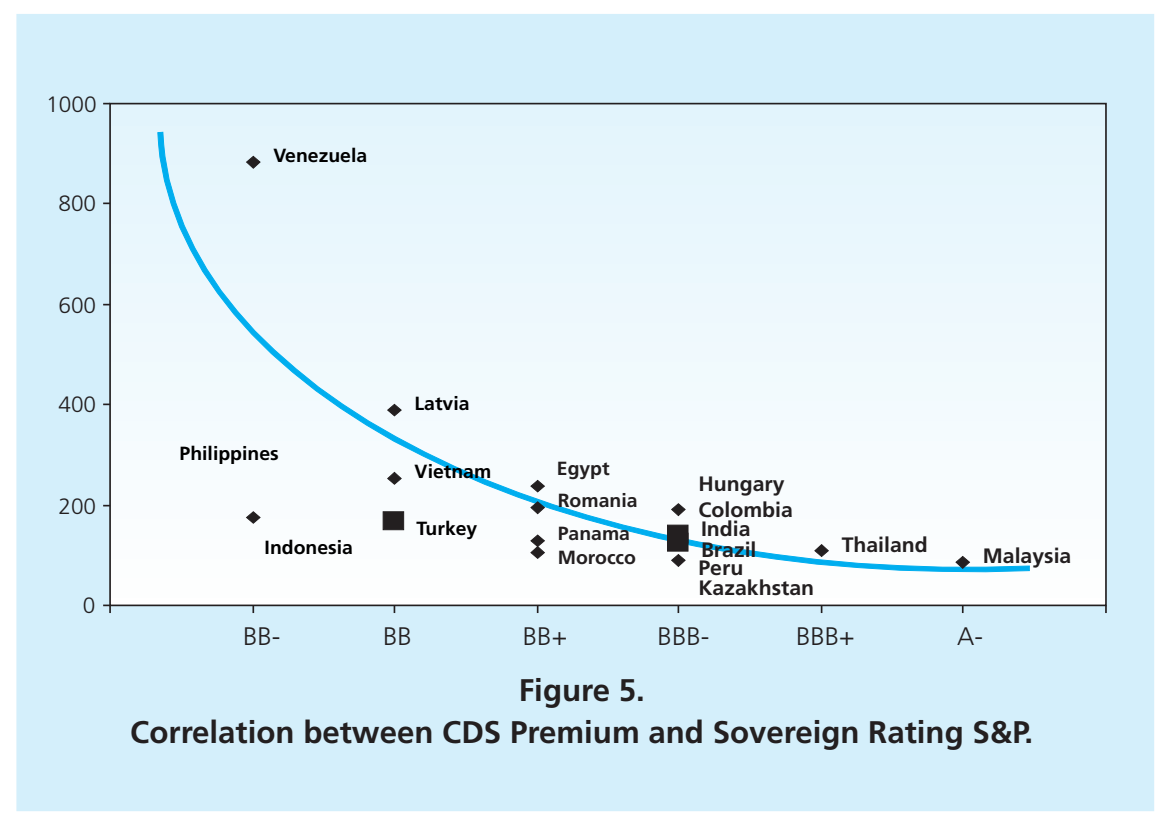

\subsection{Empirical Studies Review}

Considering that CDS is a new instrument that has just been actively traded, empirical study exploring this product is not much done yet. Skinner and Townend (2002) use linear regression approach on analyzing CDS premium. By assuming CDS as a put option, they estimated a linear model that relates premium with standard variables explaining price option such as interest rate of risk free asset, yield, and underlying instrument volatility, maturity and strike price (artificial).

Data used are 20 realization spots of CDS trade sovereign in US during September 1997 and 1999. After calculating the impact of Asian Crisis, they found that 4 of 5 variable coefficients are significant with correct signs.

Weigel and Gemmil (2006) built a special instrument (called distance to default) from statistical process, for 4 developing countries yield; Argentina, Brazil, Mexico, and Venezuela. As explanatory variables, they use various economic and market indicator that are categorized as global, regional, and country specific. They found that country specific variable only explained $8 \%$ of the dependent variance. The biggest part (45\%) is explained by regional factor especially through financial market integration. Amounted $20 \%$ is influenced by global factor (using proxy of US stock exchange return). The rest $20 \%$ variance cannot be explained by explanatory variable of the model. 
One of the leading indicators about economic problems encountered by a country is the exchange rate. Thus, it can be naturally predicted that there is a positive correlation between the exchange rate pressures with the CDS. This hypothesis has been verified by Carr and Wu (2007). By using a weekly data of Brazil and Mexico (In January 2002 until March 2005), they estimated relation between exchange rate risk variance with CDS premium through joint-diffusion model. The result of their studies showed that the CDS movement intensity is higher than the exchange rate return variance. It indicates that CDS is over estimate than its real default probability.

A study that measures the reaction of CDS sovereign of developing countries towards the credit rating movement (Standard and Poor) is done by Ismailescu and Kazemi (2010). They used data set consisted of 22 countries with daily frequency on 2 January 2001 until 22 April 2009. The dependent variable is CDS change as a function of a dummy for credit event and a group of control variables. There are 2 types of dummy, one for the credit event on certain country (country credit event) and the other is credit event for one block countries (regional credit event).

They found that credit rating event is not symmetric. A positive change announcement gives a direct impact meanwhile the negative one gives no impact. It indicates that the positive announcement gives more information than the negative one. CDS premium has an ability to predict the credit rating event for downgrade rating (negative) but not for the upgrading one (positive). The last, credit rating event will have a stronger spillover impact if the rating change is positive instead of negative.

Matsumura and Vicente (2010) started a studies focusing on default probability (latent variable) of Brazil by using five variables macroeconomic explanatory, namely the Fed interest rate, VIX: implied volatility index S\&P 500, real exchange rate, stock exchange index (Ibovespa) and interest rate swap. Daily data in period 17 February 1999 until 15 September 2004 (1320 days) is used to estimate empirical model. They found that The Fed interest rate and VIX is the most important factor in explaining the change of default probability on Brazil securities.

Bannier and Hirsch (2010) made an interesting empirical study focusing on economic function from credit outlook announcement. They use all senior unsecured debt data issued by US government and is rated by Moodys. Overall, the sample has 4043 observation; consist of 2531 upgrades and 1512 downgrades. Econometrics model used is panel linear with Cumulative Absolute Return (CAR) as dependent variable and 7 explanatory variables where some of them are upgrade/downgrade point (in notches) and out/in category dummy of investment grade. 
They found that the downgrade rating gives higher market respond compared when issuer gets into watchlist. Empirical findings also support the implicit contract hypothesis (Boot et al, 2006). In this hypothesis, watchlist has economic function to coordinate investor perception and to direct the issuer's perception.

Our study has several differences from previous studies, first, our empirical model is simpler. Using reduce form, we directly estimate the relationship between CDS premium and macroeconomic variables through price determinant variables (maturity, volatility, free risk interest rate, etc.). This parsimonious model is expected to give more intuitive insight. Second, we use larger set of developing countries panel data, from which we expect to have more comprehensive result.

\section{METHODOLOGY}

We employ linear panel data model to link the CDS and its explanatory variables. The empirical model is specified as follow:

$$
S_{i t}=\alpha+X \beta+\varepsilon_{i t} ; \quad \varepsilon_{i t}=v_{i}+u_{i t}
$$

Where $\mathrm{S}_{\mathrm{it}}$ is 5 years CDS premium of country $i$ on a period $t, \alpha$ is intercept model, $X$ is the vector of explanatory variables and $\varepsilon_{i t}$ is residual component. We assume the residual component is only one way that came from cross section heterogeneity. Thus, $\varepsilon_{i t}$ can be classified into two components which are cross section type component $\left(\mathrm{v}_{\mathrm{i}}\right)$ and idiosyncratic error $\left(u_{i t}\right)$. Residual heterogeneity can be in fixed constant form (Fixed Effect, FE) or random (Random Effect, RE). We apply the Redundant fixed effect likelihood ratio test to choose the most appropriate heterogeneity model.

There are 9 explanatory variables used in this study ${ }^{6}$. Definition, operational proxy, and relation sign expectation (hypothesis) is given in table 1. 10 developing countries are used as cross section with observation period covers 2004 until 2009 in an annual frequency. Those countries are Indonesia, Columbia, Hungarian, Malaysia, Peru, Philippine, Thailand, Turkey, Venezuela, and Vietnam. Thus, there are 60 observations in this study.

6 Some of variables in this research such as CDS, foreign exchange reserve, and VIX are converted in natural log form. It is intended to make those coefficient of estimation can be interpreted as an elasticity. 


\begin{tabular}{|c|c|c|c|}
\hline \multicolumn{4}{|c|}{$\begin{array}{c}\text { Table } 1 . \\
\text { Variables Used In Conducting Studies }\end{array}$} \\
\hline No. & Variabel & Description, Proxy dan Notation & Expected Sign \\
\hline 1 & Credit Default Swap & CDS Premium with 5 years tenor & Dependent Variable \\
\hline 2 & Economic Growth & $\begin{array}{l}\text { Annual change percentage (year on year). Real } \\
\text { GDP. (GROW) }\end{array}$ & Negative \\
\hline 3 & Inflation & $\begin{array}{l}\text { Annual price rate change percentage (year on } \\
\text { year) of consumer (INFLATION) }\end{array}$ & Positive \\
\hline 4 & Depreciation & $\begin{array}{l}\text { Annual exchange rate change percentage } \\
\text { (towards USD) (year on year) (DEPR) }\end{array}$ & Positive \\
\hline 5 & Yield Spread & $\begin{array}{l}\text { Difference between government notes payable } \\
\text { interest rate and US Treasury in } 5 \text { years tenor } \\
\text { (Y_SPREAD) }\end{array}$ & Negative \\
\hline 6 & Government Debt & $\begin{array}{l}\text { Government debt ration towards nominal GDP } \\
\text { (DEBT) }\end{array}$ & Positive \\
\hline 7 & $\begin{array}{l}\text { Foreign Exchange } \\
\text { Reserve }\end{array}$ & $\begin{array}{l}\text { State foreign exchange reserve value i on the } \\
\text { last of the year } t \text { (in billion USD, DEVISA) }\end{array}$ & Negative \\
\hline 8 & Fiscal Deficit & $\begin{array}{l}\text { Ratio between government fiscal deficit towards } \\
\text { nominal GDP (FIS_DEF) }\end{array}$ & Positive \\
\hline 9 & Current Account Deficit & $\begin{array}{l}\text { Ration between current accountcurrent account } \\
\text { deficit towards nominal GDP (CA_DEF) }\end{array}$ & Positive \\
\hline 10 & Global Risk Appetite & $\begin{array}{l}\text { VIX index value, implied volatility from put } \\
\text { option index Standard \& Poor's (VIX) }\end{array}$ & Positive \\
\hline
\end{tabular}

\section{RESULT AND ANALYSIS}

We firstly explain descriptive statistics from variables used. Then we will reveal the result of estimation gained and also analytic interpretation.

\subsection{Descriptive Statistics}

Table 2 shows descriptive statistics (all samples) from the used variables in the model. As predicted, CDS premium, foreign exchange reserve, and exchange rate depreciation are variables with the largest range. Meanwhile fiscal deficit and current account deficit are relatively stable. 


\begin{tabular}{l|c|c|c|c|c|}
\multicolumn{5}{c}{ Table 2. } \\
\multicolumn{1}{|c|}{ Used Descriptive Statistics Variables } \\
\multicolumn{1}{|c|}{ Variable } & Mean & Median & Maximum & Minimum & Deviation Std \\
CDS 5 & 256.6918 & 167.0000 & 3218.044 & 16.23000 & 433.0109 \\
GROW & 4.826263 & 5.040000 & 18.28700 & -6.730000 & 4.143712 \\
INFLATION & 8.839252 & 6.514625 & 31.90000 & -11.34632 & 8.549880 \\
DEPR & -0.329263 & -0.544737 & 30.98265 & -17.71857 & 9.601061 \\
Y_SPREAD & 5.188258 & 4.288700 & 21.63010 & -0.909300 & 4.296805 \\
DEBT & 44.94912 & 43.40000 & 81.90000 & 13.90000 & 14.97648 \\
DEVISA & 41.37088 & 33.13500 & 137.8000 & 12.63100 & 28.12098 \\
FIS_DEF & -1.992982 & -1.900000 & 9.500000 & -9.300000 & 2.955555 \\
CA_DEF & 1.272193 & 0.100000 & 17.88700 & -11.91800 & 7.430450 \\
VIX & 20.56754 & 21.68000 & 40.00000 & 11.56000 & 10.09849 \\
& & & & &
\end{tabular}

Source: Bloomberg, IMF and World Bank

On Table 3, the highest average of CDS premium is in Venezuela (865 bps), while the lowest is in Malaysia (71 bps). The macroeconomic management pattern of these countries varies one another. For instance Hungarian and Philippine are slightly loose in managing their fiscal as indicated by the fiscal deficit ratio and debt that respectively reaches $-6.25 \%$ and $68 \%$, and $2.17 \%$ and $64.8 \%$.

\begin{tabular}{|c|c|c|c|c|c|c|c|c|c|}
\hline Countries & CDS5Y & Debt & Fis_def & Y_spread & Grow & CA_def & Depr & Devisa & Inflation \\
\hline Columbia & 201.12 & 46.90 & -2.12 & 6.50 & 4.53 & -2.08 & -4.68 & 18.67 & 21.97 \\
\hline Hungarian & 122.63 & 67.92 & -6.25 & 4.35 & 1.30 & -6.89 & -1.00 & 26.38 & 5.30 \\
\hline Malaysia & 70.94 & 44.82 & -3.12 & 0.24 & 4.19 & 14.97 & -1.71 & 84.85 & 2.83 \\
\hline Peru & 176.42 & 32.60 & 1.03 & 2.71 & 6.62 & 0.05 & -2.85 & 22.67 & -1.52 \\
\hline Philippines & 264.57 & 64.82 & -2.17 & 4.56 & 4.76 & 3.18 & -2.61 & 25.40 & 5.89 \\
\hline Thailand & 86.24 & 42.67 & -0.43 & 0.67 & 3.37 & 1.49 & -2.67 & 80.76 & 3.23 \\
\hline Turkey & 215.30 & 46.48 & -2.62 & 10.66 & 3.95 & -4.60 & 2.11 & 58.08 & 8.62 \\
\hline Venezuela & 865.31 & 23.83 & 1.08 & 7.41 & 8.36 & 11.52 & 5.33 & 25.88 & 21.97 \\
\hline Vietnam & 184.21 & 34.18 & -5.63 & 5.13 & 7.28 & -6.04 & 2.87 & 16.03 & 11.40 \\
\hline Indonesia & 289.02 & 42.42 & -0.92 & 7.14 & 5.31 & 1.75 & 2.37 & 48.05 & 8.56 \\
\hline
\end{tabular}


Similar description arises from external stability. Venezuela is the most susceptible with foreign exchange reserve amounted on average 25.88 billion and annual depreciation reaches $5.33 \%$. Malaysia is more stable with average foreign exchange reserve amounted USD 84,85 billion, and its currency tends to appreciate at averagely 1,71\% per annum.

\subsection{Estimation and Analysis Result}

We estimate the model using three techniques; generalized least squares (EGLS), fixed effect (FE), and random effect (RE). Each of them is adjusted with character and heterogeneity of error component.

\begin{tabular}{|c|c|c|c|c|}
\hline & & $\begin{array}{r}\text { Table } \\
\text { Estimation }\end{array}$ & & \\
\hline No. & Dep Var: CDS & & Estimators & \\
\hline & Variables/Proxies & EGLS & FE & RE \\
\hline 1 & C & $4.050(0.00)$ & $0.623(0.56)$ & $3.851(0.00)$ \\
\hline 2 & GROW & $-0.027(0.29)$ & $-0.044(0.00)$ & $-0.023(0.09)$ \\
\hline 3 & INFLASI & $-0.015(0.01)$ & $-0.039(0.00)$ & $-0.008(0.24)$ \\
\hline 4 & DEPR & $0.011(0.21)$ & $0.00006(0.99)$ & $0.011(0.03)$ \\
\hline 5 & Y_SPREAD & $0.169(0.00)$ & $0.104(0.00)$ & $0.154(0.00)$ \\
\hline 6 & DEBT & $0.006(0.24)$ & $0.042(0.00)$ & $0.003(0.46)$ \\
\hline 7 & DEVISA & $-0.650(0.00)$ & $-0.511(0.00)$ & $-0.605(0.00)$ \\
\hline 8 & VIX & $0.861(0.00)$ & $1.457(0.00)$ & $0.913(0.00)$ \\
\hline 9 & FIS_DEF & $0.075(0.00)$ & $-0.020(0.08)$ & $0.082(0.00)$ \\
\hline 101 & CA_DEF & $0.038(0.00)$ & $-0.002(0.86)$ & $0.041(0.00)$ \\
\hline & & Goodn & & \\
\hline & $\mathrm{R}^{2}$ & 0.786 & 0.945 & 0.764 \\
\hline & Adjusted $\mathbf{R}^{2}$ & 0.745 & 0.919 & 0.719 \\
\hline & F Stat & 19.24 & 36.28 & 16.92 \\
\hline & DW & 1.36 & 2.03 & 1.24 \\
\hline
\end{tabular}

Estimation result in Table 4 shows that 6 to 7 explanatory variables have coefficient sign according to the hypothesis and are significant. Variables like inflation, depreciation, and government foreign debt ratio have lower significance level compared to others. 
The goodness of fit rate of empirical model is good. The independent variables are able to simultaneously explain the existing 76\% until 94\% variation of CDS premium. Fstatistic test are over the critical value indicating variables use in the model gives additional information.

VIX variable has the biggest coefficient, which is from 0.861 (EGLS) until 1.457 (FE). Considering that this coefficient represents the elasticity, and then a $1 \%$ of global risk perception increase encourages the increase of CDS by $0.861 \%$ to $1.457 \%$. This findings confirmed earlier study from Matsumura and Vicente (2010) as explained above. CDS as a risky asset class will experience decrease in demand when world market sentiment worsen. It also shows the integration level in derivative market in to world economic cycle.

Foreign exchange reserve is significant on the model. Estimated coefficient shows that each $1 \%$ increase of foreign exchange reserve will be followed by the decrease of CDS by $0.511 \%$ (EGLS) to $0.651 \%$ (FE). The role of foreign exchange reserve towards economic stability is highly important. First generation crisis theory expressed by Krugman (1979) and Flood and Garber (1984) shows how an attack towards exchange rate triggered by the low foreign exchange reserve. The empirical findings give support to the first generation crisis theory.

Yield spread variable with US treasury (that is comparable) becomes the third biggest influencing variable. Each of $1 \%$ increase of yield spread will give impact to the CDS increase by $0.104 \%$ to $0.169 \%$. Yield spread is actually a sovereign risk measurement, because yield is the sum of real interest rate (opportunity cost of money) and risk premium. Nevertheless, considering that yield curve is also a monetary policy tool then it is not perfect measure of risk.

Economic development, inflation, depreciation, debt ratio, fiscal deficit ratio, and current account give smaller impact but some of them remain significant. These variables are country economic specific. Thus, it can be seen indeed that these internal explanatory variables contribute limitedly; it accords to Weigel and Gemmil findings (2006).

Overall, the empirical sign and its significance have supported hypothesis expressed in this research. CDS as a market instrument has a connection to fundamental economic variables (global and domestic). Thus, the movement of CDS also reflects trader perception towards the economic prospects (sovereign risk). Furthermore, considering that this instrument is daily traded, it is possible to use it as leading indicator for sovereign risk prospect. 


\subsection{Estimation Note}

In this study, we estimate 3 variant of panel data model, based on assumption about the character of residual component. In this part, we test the most appropriate assumption to use, pooled error, fixed effect, or random effect component.

The feasibility of fixed effect assumption is tested by using redundant fixed effect procedure. Null hypothesis test technique is whether all cross section dummy is equal to zero. The Fstatistic (see table 5) is 11.433 , with degree of freedom 9 and 38 gives $p$-value $=0.00$. Thus, the null redundant fixed effect hypothesis cannot be accepted, hence the fixed effect model is sufficient to use.

\begin{tabular}{|c|c|c|c|c|}
\hline \multicolumn{5}{|c|}{$\begin{array}{l}\text { Table } 5 . \\
\text { Fixed Effect and Random Effect Test }\end{array}$} \\
\hline No. & Test Name & Statistic & Df & Prob \\
\hline 1 & Redundant Fixed Effect & F: 11.433 & $(9,38)$ & 0.00 \\
\hline 2 & Correlated Random Effect: Hausman Test & $\chi 2: 92.716$ & 9 & 0.00 \\
\hline
\end{tabular}

Random effect assumption test is carry out by using Haussmann Test Procedure. Null hypothesis in this research is that random effect has no relation with independent variable. Statistic test $(\chi 2)$ has a very big value, 92.716 , thus null hypothesis cannot be accepted. In other words, there is correlation between random effects with independent variable, so RE specification is bias.

Both of the above tests show that FE technique is the best one in modeling correlation between CDS and any independent variables. In addition to this specification test, considering that our model involves lots of independent variables then multicollinearity might be an issue. Even though the existence multicollinearity does not evoke bias in parameter, however bias on variance can complicate the conclusion. In this study, we use simple procedure to test the multicollinearity through bivariate correlation value.

From the table 6 , it can be seen that bivariate correlation coefficient value among all independent variables stays under 0.5 . Early detection of multicollinearity is the presence of bivariate correlation coefficient above 0.8 . Thus, it can be concluded that multicollinearity does not become issue in this empirical study. 
Table 6.

Bivariate Correlation Coefficient among Independent Variables.

\begin{tabular}{l|c|c|c|c|c|c|c|c|c} 
& GROW & INFLASI & DEPR & Y_SPREAD & DEBT & DEVISA & FIS_DEF & CA_DEF & VIX \\
GROW & 1.000000 & 0.081179 & 0.103939 & -0.059887 & -0.285217 & -0.368460 & 0.252166 & 0.203625 & -0.242872 \\
INFLASI & 0.081179 & 1.000000 & 0.141508 & 0.549710 & -0.267108 & -0.317948 & 0.012775 & -0.003054 & 0.187736 \\
DEPR & 0.103939 & 0.141508 & 1.000000 & 0.263004 & -0.068855 & -0.022814 & 0.064825 & -0.003557 & 0.377171 \\
Y_SPREAD & -0.059887 & 0.549710 & 0.263004 & 1.000000 & -0.132355 & -0.215354 & -0.121660 & -0.345598 & 0.372907 \\
DEBT & -0.285217 & -0.267108 & -0.068855 & -0.132355 & 1.000000 & -0.106676 & -0.430229 & -0.252147 & -0.248663 \\
DEVISA & -0.368460 & -0.317948 & -0.022814 & -0.215354 & -0.106676 & 1.000000 & 0.068382 & 0.342828 & 0.250980 \\
FIS_DEF & 0.252166 & 0.012775 & 0.064825 & -0.121660 & -0.430229 & 0.068382 & 1.000000 & 0.469138 & -0.004423 \\
CA_DEF & 0.203625 & -0.003054 & -0.003557 & -0.345598 & -0.252147 & 0.342828 & 0.469138 & 1.000000 & -0.098183 \\
VIX & -0.242872 & 0.187736 & 0.377171 & 0.372907 & -0.248663 & 0.250980 & -0.004423 & -0.098183 & 1.000000
\end{tabular}

\section{CONCLUSION}

This study has reviewed the existing literatures on the correlation between CDS and fundamental economic variables. Considering that CDS is a derivative instrument (analogue as option) then valuation theoretically depends on free risk interest rate, maturity, strike price, volatility, and spot price of underlying asset.

Some of empirical studies have shown a tight correlation from CDS attitude towards fundamental economic. Study that is done by Ismailescu and Kazemi (2010) shows the existing correlation between CDS and sovereign rating change. Following Standard \& Poor (Beers and Cavanaugh, 2006) method, economic fundamental variables that influence to rating can be divided into 7 categories; political risk, aggregate economic structure, economic growth prospect, fiscal policy and condition, monetary, external, and contingency position (domestic and overseas). Changes on this fundamental variable can be presumed that it would influence CDS premium through variable pricing.

The current study tests the dataset that consists of 10 developing countries on period 2004-2009. The result shows that global risk sentiment ( using XIV index as proxy), foreign exchange reserve and yield spread are the most influencing fundamental variables toward CDS premium.

These findings give some policy implication as follow:

a. It is necessary to monitor the global sentiment and reduce the negative impact of the deterioration through better international cooperation. 
b. Sufficient foreign exchange reserve is necessary as a buffer if an immediate negative shock occur. High foreign exchange reserve can also become a signal of external sector credibility and stability.

c. Monitoring any movement of bond in the market is highly important. Yield spread is an indicator towards sovereign risk perception change. 


\section{REFERENCES}

Bank for International Settlement, Triennial Quarterly Survey, Derivative Market, September 2010.

Bannier, C.E., and Hirsch, C.W., 2010, "The economic function of credit rating agencies What does the watch list tell us?" Journal of Banking and Finance, Vol. 34, page. 30373049.

Beers, D.T and M. Cavanaugh, 2006, Sovereign Credit Ratings: A Primer, 2006, Standard \& Poor's Research.

Cameroon, A.C., and Triverdi., P. K., 2005, Micro econometrics: Methods and Applications, Cambridge, New York.

Cantor, R., 2004,'“An Introduction to recent research on credit ratings", Journal of Banking and Finance, Vol 28, page. 2565-2573.

Carr, P., and Wu, L., 2007, "Theory and evidence on the dynamic interactions between sovereign credit swaps and currency option", Vol. 31, page 2383-2403.

Hull, J.C., 2011, Fundamentals Of Futures and Options Market., 7th Edition, Pearson.

Ismailescu, I and Kazemi, H., 2010," "The reaction of emerging market credit default swap spreads to sovereign credit rating changes", Journal of International Banking \& Finance, Vol. 34, page 2861-2873.

Matsumura, M.S. and Vicente, J.V.M, 2010," "The role of macroeconomic variables in sovereign risk", Emerging Markets Review, 11, page 229-249.

Nomura, Fixed Income Research Team, Credit Default Swap Primer, May 2004.

Skinner, F.S and Townend, T.G., 2002,"An empirical analysis of credit default swaps", International Review of Financial Analysis, Vol. 11, page. 297-309.

Weigel, D.D. and Gemmill, G., 2006, "What drives credit risk in emerging markets? The roles of country fundamentals and market co-movements ", Journal of International Money and Finance, 25, page 476-502.

Whetten, M., Adelson M., and Van Bemmelen, 2004," "Credit Default Swap: A Primer" , Nomura Fixed Income Research. 
This page is intentionally left blank 